\title{
PSYCHOLOGICAL DISCONTINUITIES IN THE LITIGATION PROCESS*
}

\author{
ROBERT S. REDMOUNTí
}

IT IS PROBABLY not at all unusual for the immediate consumers 1 of litigation processes, the litigants, to feel that the results they get from law are obtuse. Litigants are actualizing agents for the processes of law, but what happens to them thereafter in legal processes may have little to do with their entering needs and dispositions. This is because there are notable psychological discontinuities and irritations in legal experience, at least from a litigant's viewpoint.

Litigant aims and needs, attorney analysis and tactics, and law's structural apparatus for producing litigation decisions-courts and trial procedure-each have disparate psychological characteristics. In their psychological attitudes, they frustrate and may interfere with one another.

Mostly, it is the litigant or litigants-the direct consumers of litigation processes-who are injured. Their aims and needs are excluded or ignored. And, it is precisely this consequence that the legal profession can ill afford and would do well to avoid in the existing highly competitive market for appropriate skills and services.

\section{The Arms of the Litigants}

Litigants, in forming a contest, are generally responding to their individual senses of frustration. In psychological terms, they seek relief from phenomenal experiences of discomfort or unhappiness. Theirs is an unsated psychological appetite, to be served by the strength

* The congealing of the writer's thoughts, as expressed herein, is partly the result of the stimulation afforded by a Law and Psychology Seminar given at the New York University School of Law in the Summer of $\times 958$, which the writer served as consultant. Responding to the separate legal interests of Professor Delmar Karlen and the members of the Seminar, he was able to probe and reflect upon various functional ties between law and psychology. A substantial debt to this group is acknowledged.

† A.B. 1943, M.S. x 947, Pennsylvania State University; Ph.D. x 949, New York University; LL.B. 1957, Yale University. Member of the Connecticut bar; Certified Psychologist, New York. Author of several articles relating psychology to law. 
of their social and economic, and perhaps ethical, resources in an effort to check and redress frustration at its source.

A deprived party, or one about to be threatened with deprivation, senses frustration. Unjustifiable loss, the continuing risk of injury, an unfulfilled agreement, are typical plaintiff's causes that reflect a condition of frustration, particularly where the party is a real and nonfictionalized entity. The threat of injury to him or of defeat-the prospect of deprivation-is generally the agent fomenting the sense of frustration in defendant's causes.

For both plaintiff and defendant, there is loss or fear of loss, in a psychological as well as in a material sense. For each, there is the risk that frustration will run deeper, in that there will be some permanent change of condition requiring some forced reorientation in patterns of adjustment or living. The aim, in resolving frustration through the offices of law, is partly to avoid such risks and consequences. The party suffering in a case of tort does not want to be left permanently lame; at least, he wants to be able to reassert his position and condition of living on some successful basis. The party fearing some form of trespass does not want anxiety to be a marked and continuous condition of life, nor does he want to contemplate or face the change and loss with which he is threatened. Offenders, criminal and civil, generally prefer to avoid changes in their habit of life and adjustments in particular circumstances, that a successful lawsuit against them threatens.

It is the sense of frustration, backed by feelings of fear, that impels parties toward legal recourse. Frustration relief, the dissolution of fear, and the nearest maintenance of an established and familiar condition and pattern of life are the aims they seek to effect through the use of legal services.

Litigant dispositions and aims may be complicated at times by another feeling-hostility. This takes the form of a retributive attitude, for the frustration and harm that has already been induced and for that which is threatened. It appears as though there is a primary interest in destroying the other party or, at least, crippling him or rendering him ineffective, psychologically and perhaps materially. Usually, the feeling is fairly subdued in brief time because it is mostly reactive in nature and generally has little to sustain it once it is experienced. It is a feeling held without any immediate contemplation of a realistic and socially purposive aim. When it does attach itself to the latter, then feelings of hostility have become welded or submerged in feelings of fear. Once again, some perceptiveness of the litigant's own condition, 
or threat to it, prevails. The desire to "get" the other or "get even" resolves itself into trying to make the best adjustment and solution the situation will allow.

Mostly, however, when a party approaches his attorney and perhaps even later, when they go to court, the party's sense of frustration may be rendered acute and may be complicated by urges based upon hostility as well as upon fear. 'The attorney, initially, likely serves as an emotional buffer. He must cope with hostility and allay fear.

Parties, however, generally do not approach the law and attorneysat-law in terms of naked emotion and emotional demand. These have been tempered by evaluatory attitudes that bring into account social and moral considerations. Even in reaching for the approach of law, parties have themselves begun to treat their psychological condition by assessing where it stands in a world of social reality. Already, it may be consciously recognized that the basis of frustration will endure and that fears will be realized. Parties may have to live with disappointment and dissatisfaction, and orient themselves about it. Irremediable social and economic loss in the employment of legal processes may be so large that relief from feelings of frustration may be available only on a severely limited basis. A wrongful death, destroyed or inaccessible property, a profit opportunity irretrievably lost, the certain prospect of imprisonment whether on a greater or lesser charge, are events where the effects of frustration may be relatively fixed.

On the other hand, the element of social or economic loss, threatened or existing, may be relatively negligible. The element of fear underlying the sense of frustration may be easily dissipated. Hostile feelings, uncomplicated by fear, may more quickly subside. As instances, the loss due to tort may, in the context of one's experience and wealth, be slight. An unfavorable decision, resulting in the possible assessment of monetary damages, may prove but a slight strain to the capacities of some to endure the loss.

The ethical circumstances causing and affecting a party's state of frustration may also bring about some realizations as to the likely disposition of the emotions of fear and hostility that have been generated. A weak moral or legal position, involving the idea that one is at fault or that others will find one at fault, again suggests ultimate dissatisfaction and disappointment. A party will have to "eat his feelings" in some way. "The consequences of negligence may have to be faced where there is no prospect of absolution, justification, or mutual 
fault to enable blame avoidance. Creating a nuisance invites the prospect that an injunction will follow, and so forth.

On the other hand, a firm and righteous ethical position may tend to liven and strengthen feelings of frustration and lead to stronger demands for vindication. One is outraged and finds the prospect of loss the more intolerable where it is due to another person's deceit or recklessness or viciousness.

To summarize about litigant needs and dispositions, it is feelings of fear and hostility, possibly tempered or whetted by the evaluation of circumstances, that bring him to an attorney. The feelings are uncomfortable, and there is a sense of urgency that they be dissipated. At stake is the sustaining of a position in life. Failing or substantially delaying in properly attending to the feelings and needs results in the loss and disturbance of meanings and values. Loss and disturbance are generally uncomfortable experiences that most people prefer to avoid.

The litigant's interest is to achieve successful continuity in experience by resolving his sense of frustration. Where his social and ethical position in the matter is not sufficiently clear, he comes to the attorney first for clarification and for as much support as an attorney's better knowledge and skill can give him. Either as a direct result of his own troubled emotions or as a consequence of the attorney's influence on his emotions, he seeks the swift resolution of his frustration through a convincing denial or overpowering of his opponent. But, ultimately, what is really necessary and important to the litigant is that he avoid the possibility or the effects of abrupt change. The need to prevail, if it is analyzed correctly, is the need to survive and to maintain patterns of adjustment and relationship. What, at first blush, is the need for partisanship and the application of force, a crude and determined attitude but without the evidences of much reflection or deliberation, sooner or later resolves itself entirely into a focus on the possibilities and means for establishing or maintaining satisfactory terms of relationship in life. A litigant may ultimately have greatest need for an attorney with mediating skills and attitudes, so that his frustrations, benefits, and risks may be better measured and adjusted.

The attorney is an emotionally significant figure to the litigant, and his relationship to the latter is a process involving a complex of skills and sensitivities. The more blatant and obvious adversary role of the attorney ought not to blur the importance that he be skilled in sensing and responding to his supportive and clarifying role with his client, and 
that he be trained and capable in the process of conciliating between litigants.

\section{Attorney Analysis and Tactics}

The attorney, for his part, measures the reason and the power in his client's position. He takes an evaluatory attitude at the outset. He responds not so much to psychological discomforts, but to the strength of the litigant's position from a common sense social and perhaps ethical perspective and from a technical legal view. He judges the litigant's position on a social and legal chart and assesses the probabilities that it can be advanced. His objective is to set a course of strategy that will achieve the maximum legal advantage.

Mostly, the attorney's response in the situation is not to the litigant and what the latter is feeling. In assuming dominion over the case, he leaves the litigant behind, only to catch up with the latter at the end to present whatever benefit is forthcoming from his efforts. Likely, the litigant, on the sidelines, will have traversed a series of attitudes that add up to frustration in the attorney-client relationship. The first experience is that of hope, as the attorney places his resources at the disposal of the client. Then there is puzzlement, as to how and to what extent the attorney is actually attending to his needs. There follows exasperation, as one waits in vain for definition or result. Finally, there is resignation, so that any favorable result achieved by his attorney comes to the client almost as a complete surprise and is not infrequently anticlimactic.

The attorney's actions are mechanically planned and methodic, and are seldom invested with any sense of urgency either for himself or for his client. With the possible exception of certain urgent suits for injunction, he hardly glances at the client's predicament and accepts as the norm the fact that materializing a case in law takes unmeasured time. And, he assumes that the details of the legal outcome are in themselves sufficient reward and satisfaction for the client. His efforts are hardly calculated to do more.

In a word, the tenor of the attorney-client relationship is, perhaps characteristically, marked by insensitivity. Delay amounts to the prolonging of frustration, to the point where a litigant's fears that he may have to suffer acute and continuing discomfort are substantially realized, often regardless of the ultimate legal outcome. Hostility, instead of being resolved, may seem all the more justified, though the target may 
be diffused so that it includes the processes and operatives of the law as well as the opposing party. Inattention on the part of the attorney in relation to his client is the source of unfriendly feelings and feelings of irritation directed at the attorney. They are only more strongly emphasized, though not necessarily expressed, when a client feels he must rely on his attorney and on the processes of law for the satisfaction of his needs.

The attorney-client relationship is, in most circumstances, psychologically difficult anyway. The attorney must tailor the client's situation to that which fits within the operations of law. He cannot, in making his case, recognize the "irrelevancies," such as personal feelings and the extended implications of the outcome, that are of the greatest importance to the client. Even his best diligence cannot prevent the delays that have become a hallmark of legal processes. Further, his analysis of the case, and its prospects in law, may result in an invitation to the client to subdue his feelings and change his viewpoint. The attorney is an instrument in conflict whose partial effect is to force clients to face reality, and this is frequently not a happy prospect. Facing reality, where reality already affords the possibility or the likelihood of damage, is frustrating. The attorney's skills and the law's scope probably fall short of client satisfaction, though to a degree that is perhaps unnecessary.

The bargaining between attorneys, an important characteristic of the legal process, has some attributes that are another source of psychological annoyance. It jolts the sense of dignity, of fairness and order, with which the layman tends to invest the processes of law.

The attorney jockeys with his opposing number in an effort to de- . velop a maximum position of strength for his view and, ultimately, to gain the entire decision. In this sense, pleadings, motions, and the like, and the maneuvers relating to them, represent mostly jostling for position in order to develop a particular basis for outcome. Pretrial hearings, conferences between attorneys, and so forth are further instances of maneuvering, and they are generally oriented toward delivering a decision. They are all modes in the bargaining process.

Skill and daring are the essential elements of bargaining, the more so where the range of possible outcomes is large and where particular outcomes may be drastic. The bargaining attorney attempts skillfully to knit together the absolute truth as he knows it, selected elements of such truth that lend themselves to particular implications, embroideries that tailor the truth to a particular perception, and, sometimes, sheer 
pretense and falsehoods. His effort is to induce accurate perceptions if his position bears power and vitality on its own merit, or false perceptions and perceptions that are false to varying degree where he must "jack up" his case. Generally, falsity takes the form of exaggeration and solicits an emotional reaction, that of fear. Whether the element on which the attorney capitalizes is truth or a degree of falsity, power is asserted, created, and gambled in an effort to induce fear. Both truth and liberties with the truth are fairly taken for this purpose. It is, for the attorney, a part of the game, a tactic that influences the outcome. The tactics, taken on their own terms among others who are familiar with and practice them, bring success or failure. Seen from a distance, however, a more likely percept is that the attorneys engage in ethically questionable practices, with impunity, in the name of an ethical result, and pass these off as "little white lies." The effect is further adulterating because "sophisticated" clients then learn to expect and depend upon the "little white lies."

The attorney feels pressed for the result because the commodity he visualizes as his contribution is, in psychological terms, tension reduction through the development of a better position of advantage as against adversary parties. In this role, the attorney cannot afford to be neutral as between the litigants. Manipulations and compromise, for no other reason than to achieve the best possible partisan success, would appear to be necessary.

There are, of course, substantial differences between attorneys. The more conservative-minded, with fairly stringent personal ethical codes, eschew sharp practices. They seek to develop and maximize the element of truth, and they disdain falsity. Other attorneys have lighter regard for the truth and greater regard or need for personal success. Only an analysis of the psychology of the lawyer in his professional work and an analysis of the economics of law practice will account for such a wide range of difference.

Then, too, situations provide for different expectations regarding the serviceability of truth. A fairly certain position, mostly impregnable from ethical, social and economic, and legal attack, renders adherence to the complete truth easier. It is where relative positions are uncertain, or where one is at a disadvantage, that inclinations to utilize some shading of the "white lie" technique are most likely to be fulfilled.

Litigants and others catch glimpses of the bargaining processes. At times, if they attend well, they may see more and may develop a fuller view of the deception that is being attempted. The result is a new 
psychological dimension in a person's experience with the law. The litigant's position and his viewpoint are elasticized in order to serve maximum personal advantage. "Stretching the truth" is not an uncomfortable experience to many, but the degree of stretch may generate uncomfortable feelings.

The litigant, of course, wants to be relieved of the fears and hostilities that triggered the operation of litigation processes in the first place. Within limits of moderation, that which achieves this end gratifies his needs. However, promiscuous liberties with the truth and, one might add, with a litigant's firm convictions create further feelings of exasperation, of guilt and embarrassment. A reasonably principled litigant may feel an added disturbing element in litigation that affects his sense of right and justification in relation to the other party and affects his own self-respect.

The operation of law, notably in the bargaining aspects just mentioned, may prove an embarrassment that one wishes to escape. The shadings of a new conflict emerge at this point. The litigant must choose between the advantages he seeks in particular end results and the avoidance of discomfort associated with how one goes about it. There are likely some litigants who quickly disassociate themselves from the process. Aware of it one time, they may thereafter settle more readily in order to avoid the embarrassments of litigation. If involved in litigation, they may quickly settle or drop their cases. The new element of frustration, added to their existing load, in effect forces them to accept a reality position they do not like, and they can blame law and lawyers for it.

Likely, there are a greater number of litigants who accept their lot in the process of litigation without active protest. They do so by rationalizing that this is the operation of law, the ethically impregnable, and one should not, as a general rule, call into issue either its method or its result.

Most frequent, perhaps, is the litigant attitude that he will accept the result of law bargaining and law operation, but he will turn his head and disclaim responsibility for its practices. He will leave it to the attorney to handle the dirty business, with an attitude that connotes his dependence upon the recognition of power, but not respect. It is a feeble deception for the litigant, but what is more important of note is the attitude toward law and lawyers and the way it is cultivated. Exposure to lawyers and the operations of law sap the respect that generally comes with the idealized image of law operatives and processes. 
In fact, it is replaced by a debasing attitude and by a cynicism that poorly shields the hostility that is felt.

If one must rely upon the operations of law and upon attorneys, one does so because there is important power to be found here. However, the experience, even with a "good" result, does not lead to a full feeling of gratification. It may actually be quite uncomfortable, even without the uncertainties of outcome. Psychological contamination of one's feelings is an important stake for the litigants and, parenthetically, reasonably for the attorneys, too, when the process of bargaining goes on. Nobility or success, in terms of outcome, is simply not enough to cloak the matter.

\section{III}

\section{Courts and Trial Procedure}

Mostly, litigants look to the office of the court and to trial processes for character. In the public image that they carry, an image mostly unburdened by intimate experience, they are unimpeachable. They are the conservators of integrity. It is in the esteem of this value that litigants seek their "day in court," expecting that their own integrity will be recognized, fairly treated, and upheld.

Courts and trials deliver this expectation and reinforce it in certain of their operational characteristics. They seek to emphasize the importance of order and discipline as a basis for creating decisions and promoting adherence. Court jurisdiction, courtroom decorum, trial procedure, and the rules of evidence all share in these psychological purposes. They are the means for establishing and interpreting the experience of parties. Theirs is not a guarantee of truth, inhering from their very nature, but a means to system and the cultivation of respect which render decisions and decision-making acceptable and binding.

The order and discipline involved in court structure and trial processes are imposed upon the litigants. They represent an insistent demand that litigants share and respect these values in the way that the law allows. Mostly, they do capitalize upon logic and recognize the importance of utility in the forms and emphases they take. However, the major tendency among those whose profession is law is to ascribe to them an importance that transcends practical necessity. Their abiding significance is posited in terms of the ultimate values that the system of law expounds: order and discipline and respect. These are to be the monuments of court and trial experience. 
The attempt to order and discipline provides definition not only for experience, but for the mode of interpreting experience. Comparatively little is left to uncertainty. To many, this is a source of reassurance about the law. Definitive structure and operations are the source of abiding and insuperable strength and provide a basis for confidence. In courts and trial processes, there appear to be the measure of unsurpassable certainty. And, in the clarity that definition provides, the processes for testing and assessing a party's position would appear to be revealed. On this account, that they are revealed, they offer a better prospect of fairness, and fairness is a crusading banner for a litigant who feels wronged and frustrated.

The misfortune is that courts and trial processes do not live up to their idealized image. For explanation, there is more than crassness and chicanery to consider. With a little discernment, one can perceive that the very attitudes which afford the particular strength and signifcance of courts and legal processes supply its weaknesses.

Discipline and order, certainty and definition in the broad realm of human experience are presently unobtainable objectives. They can be approximated, though none too well, and the result of an effort of this kind is to contribute injustices to the interpretation of experience. Froin a litigant's viewpoint, and often from an attorney's as well, the conforming of experience to such discipline and order, and certainty and definition as the law recognizes has only the effect of creating insensitivity and reflecting rigidity. Perceptiveness and feeling are lacking, to a degree that antagonizes.

Mostly, litigants, and particularly their attorneys, are not willing to be overcome or transformed by the imperial qualities of court struc-. ture and trial processes. They have their own practical aims to follow. The fixity of court attitudes and trial processes, to the point of blindness, renders their manipulation easier. One knows just how far procedural requirements need be satisfied. The realm beyond, which is likely to entail the larger and more significant elements of experience, is a legal netherland to be freely exploited by enterprising persons who tenaciously hold to their own ends. Often, one can observe the formalities of compliance with court requirements and trial procedure and casually or cavalierly abuse their spirit.

The comparative inelasticity in the requirements of court order and trial procedure are well-known and celebrated. They exist to the degree that an attorney's trial objective is commonly not only to outmaneuver and overcome his opponent, but also to do the same in regard to the 
formal requirements of court and trial that hinder him. This is so notwithstanding gradual enlightenment about the complexity of experience that has contributed to technical changes, emancipatory in character, in trial procedure and the rules of evidence. Perhaps the most evident instance is the experience with bias and prejudice-not the studied and obvious kind, but the more subtle manipulation of attitudes of triers of cases through the influence of their emotions alone. Treatises on trial tactics are rich in demonstrations of milder examples relating how this may be done. If one reads closely and gets the proper spirit, they provide a blueprint of thoughts and attitudes that cultivate emotional exploitation. The need to introduce bias and prejudice of this kind is an essential quality in an attorney's partisan effort. His common sense informs him that decisions, nearly all decisions by nearly all people, have some emotional basis. Many efforts of this character are not, however, permitted in the front door because of rigid declarations about their impropriety and their disorderly quality, either as a means of influencing decision or as a basis of decision. It is as if declarations of rules and decorum could sweep away native endowments in the presentation and evaluation of experience.

Rigidity, both in the principles and in the operations of courts and trial procedure, produces the effect of undermining the very value that litigants and others most respect about courts and trials: integrity. The integrity of party causes and objectives is further sacrificed in trial because of the degree of impotence of courts and the law in safeguarding their own integrity. The ravishment of the stated law is too common a spectacle in trials to afford confidence in their decisions. This is particularly the attitude when once a litigant has been to court. He recognizes, if his previous experience has provided some measure of success, that he has had more good luck than vindication. Henceforth, he is likely to approach the processes of law with a certain jaundice and approbation, knowing, or at least questioning, whether it can live up to its promise and appearance.

Rigidity in the premises of law, either in regard to its own operation or in regard to experience generally, leads to another and related untoward consequence. Mostly, these premises are saving of effort, but, at the same time, they sharply distort the reality of experience and create resentment and perhaps disbelief for the results they cause. They encourage exaggeration of the characteristics and merits of a case. One of the more familiar instances is the generally accepted concept of contributory negligence in tort actions and the standard of judgment it 
provides. Toward whosoever favor the rule runs in practice, it has the effect of totally absolving a litigant from blame. There is, in this concept, no middle ground in which culpability is shared and relative, according to the nature of much experience. Another example is the application of the concept of consideration in contract actions, consideration being purposed as the affording of a quid pro quo in a transaction. Determinations relative to consideration that fail to take account of its true and specific value in a transaction merely exaggerate or misrepresent real circumstances. Mechanical findings that suffice only in the recognition of consideration without real regard for its value create grotesque effects. They develop strength, verity, and justification, or the reverse, in a litigant's case where, in truth, such extreme interpretations of experience are erroneous if facts are reasonably observed.

Some more certain rules of procedure also are particularly limiting, to the point where they hinder or prevent a fuller and proper assessment of experience, and tend to contribute to false or arbitrary impressions. They generally have the effect of honoring single and isolated occurrences in experience and fail to give sufficient view of the continuity and context that gives experience significance. Character is assessed in this manner. Credibility and competence are also established on the basis of rules that seem to regard the truth in behavior as a matter of developing simple and isolated observations, and then performing a simple additive operation.

Litigants may justifiably take offense at the cavalier manner to which their experience is treated. They may feel strongly that the element of fairness, which alludes in part to the correct interpretation of experience, is missing. Even where they gain an unearned advantage, it is certain that they have not, through their personal experience, cultivated respect and appreciation for legal processes. Even the strength of law, though it cannot be denied, is seen to be arbitrary and too insensitive.

The effort narrowly to confine the interpretation of litigant's experience and rigidly to limit their presentation and analysis, all occurring within a framework of rank partisanship, contributes another perverse effect. It encourages and nurtures hostile and aggressive behavior, deploying words as slings in an effort that is predominantly characterized by its destructiveness. The tendency toward destructiveness already exists in the unresolved hostile feelings of litigants and in the limited technique of attorneys in seeking to impress and subdue one another with an indication of the destructive power inhering in their clients' arguments and positions or in their own skill. The rigid con- 
finement of experience and expreession in rules of law and trial procedure makes its own contribution to the aggressive trend. Confinement and limitation, particularly if it is unduly narrow and unreasonable, creates frustration. The most familiar and immediate counteraction to frustration is aggression, and in this instance, it takes the form of destructiveness. There is a loosing of aggressive emotion directed at convenient targets, generally not in native form, but manifested as an intensity connected with certain operations of the trial process. The most obvious example is cross-examination. The attorney is permitted pointed expression, and there is severe restriction in the selection of response that can be given here. Aggressive inclinations and feelings are concentrated in the effort and in the opportunity to "destroy" witnesses and opposing parties simultaneously. Both rules of evidence and court decorum permit this process with only slight restraint and little concern for the human dignity that is being maltreated. The rationale that justifies this practice is that there is a need to overcome obscurity and, whatever other consequence, this is the way to do it.

Attorneys, generally well-schooled in dialectic that carries with it at least the collateral tendency toward aggressiveness, frequently use each other as targets. In the highly specific and narrowly confining rules of trial operation, they find the opportunity to exploit aggressivedestructive tactics and tendencies. They invoke the narrow rules that they know will generally be rigidly upheld in an effort to harm and weaken, to embarrass and belittle, and to disturb and upset one another.

In some instances, inherent qualities in concepts of substantive law contribute to the aggressive and destructive characteristics in the trial process. Perhaps the most obvious example is the contested divorce case, where substantive law and the idea of culpability solicit lurid details and the probing of private lives to a degree and in a manner that is clearly aggression upon the litigants and subjects them to added indecencies. The degree of the law's and lawyers' insensibilities to the emotions and effects they create is sometimes astounding.

Unfortunately, trial is too frequently a spectacle, notable for its abusive features. The abuse is often disguised as necessity and as mere convention by which trials can come to a decision. The abusive features are encouraged by primitive notions as to how one determines the truth and influences others. Verbal aggression is a mode of emotion-probing and emotional appeal seeking to arouse primitive inclinations toward hostility and resentment. They, in turn, stimulate behavior and effects that suggest weakness or impropriety in the respondent, and these are 
the conduits of judgment. The assessment of probity very often does not go beyond recognizing the immediate effects that a successful verbal attack can generate. The effect on observers is to stimulate their emotions, hostile or compassionate, without providing insight.

The trial process, in large part, is still very much antediluvian, mostly in that it presents the qualities of an historic ordeal. It is rigid and limited in its perceptions of experience, stresses qualities of its own that are considered to be transcendental, and is aggressive and destructive in nature. It tends to belittle human dignity in its manner and lets loose base emotions that are actually the most obstructive to the development of both the idea and the effect of discipline and order. The worst effect of the ordeal is upon the litigants. Aside from the intermediate injury or embarrassment they may have to suffer, the outcome of litigation is mostly uncertain for reasons that may have little to do with the character, the appeal, or the necessity of their cases. In the end, the processes of trial seem hardly intended for them, though they must suffer its consequences. They may feel the processes of litigation to be a foreign agent and not the instrument of personal service and benefit that it should be in matters of party dispute. And, as if to make the rankling complete, alienation is further achieved by the fact that the entire trial process for the litigant is marked by substantial obscurities and, too frequently, by interminable delays.

\section{IV}

\section{The Psychology of Litigation}

Miscreant litigation effects are the result of intertwining two substantially differing sets of assumptions regarding the psychology of litigation.

The generally prevailing psychological rationale is that the litigant mostly wants the harming or disarming of his opponent and will go to great lengths and easily tolerate abuses for this end. The issue is a matter of personal dominance as the means to preserving a sense of strength and well-being. Litigation basically concerns the competition to achieve superior positions in life. The basis of dominance is power, and the litigant hires experts, notably attorneys schooled in the process, to reflect and exploit his bases of power as the means to achieve his success and superiority. Finally, because power and the struggle for superiority blight sensibilities so completely, there is the need stringently to regulate the litigation process so as to prevent abuses. Substantial order and regularity are needed to harness and contain primeval 
struggles almost literally within the bounds of reason. In fact, the assurance of civilization in the litigation process lies in constant vigilance over, and in the perpetuation of, the legal structure that generates order and regularity. The abuses that do occur merely represent the limits of effective containment of drives toward dominance and their meter of success, power. The proper focus is on the success of litigation as an ordering process and not upon its lesser limitations as evidence of failure.

A developing alternative in a psychological view of litigation reflects a different state of society. The emphasis is not upon individual power, but upon the sense of community. The litigant's prior concern is with self-preservation, but beyond the necessities of this aim, he does not, upon reflection, wish notably to harm or to alienate his opponent. Preserving integrity and the means of relating to others is important, and these together are of a different quality from expanding or sustaining individual hegemony.

Achieving success, but at the same time limiting ruination, is the task of the attorney. He must probe for solutions, capitalizing upon personal sensitivities and great flexibility of skill. Parties are momentarily incensed to great mutual intolerance, but their aims are misread if they are assumed to require only individual dominance, almost by any means or at any kind of cost. The attorney more profoundly fulfills his function when he evidences greater insight and skill, and better enlightenment and understanding than his client. He goes beyond the latter's momentary blindness and intolerance to a result that is, in truth, more nearly cherished and anticipated by the latter.

In this posture, formal legal procedure is designed only to produce insight and bases of understanding. Decisions must facilitate continuities in experience, and not further frustrate relationships. A sensitive and effective resolution of conflict is the objective, and substantial preoccupation with the elements of procedural order and stringent regularity may prove a considerable hindrance. Enlightenment, comparatively more so than order, is needed. This calls for a sharp reduction in restrictive practices, emphasis on more flexible procedural attitudes and approaches, and the cultivation of self-discipline and greater mutual respect in the operatives and operations of litigation.

Current trends in litigation reflect a misalliance between the two discordant psychological views, but it is the second, or community and conciliation view, that is increasingly displacing the first, or individual dominance and power view. 
The attorney in his professional capacities does not reflect the degree of change that would be compatible with an enlarged and more difficult role. In his formal training and preparation, he learns little or nothing about clients and their needs. He develops no sensitivity for the requirements of his practice in relating to and understanding his client.

The attorney's concept of bargaining or working for a result is based mostly on the manipulation of power. He wields power in an effort to seek mostly dominance or mastery over his opponents, both for himself and for his party. His communication and participation in the bargaining process emphasize mostly antagonistic feelings. The greater need is for understanding the subtleties of human interaction processes, so that one can relate to others and effect analyses and results on the bases of more than the single dimension of power and the tactic of aggression. The power orientation and the exploitative, aggressive personality are substantially overemphasized in the professional development of the attorney.

Formal trial processes have evidenced greater change. The liberalization of pleadings and joinder, the burgeoning use of the pretrial conference, the liberalization of rules of evidence so as to admit more material into testimony, the larger range of discretion given the judge to exercise his judgment according to the needs of individual situations, are instances that reflect the growing skill and flexibility of courts to cope with controversy and develop decisions in a more sensitive and effective manner.

The changes reflect some shift not only in the choice of values that guide litigation processes, but also in the psychological assumptions that attend the decision-making process. Insightful and sensitive decisions are the result of complex thought and feeling processes. These probably seldom rely upon, and they are seldom represented in, great complexes of regulation, such as those manifest in more rigid definitions of trial procedure and rules of evidence. The decision-maker responds as a total personality. His behavior and responses to behavior are not regularly restricted by elaborate rules designed to limit and guide his intellectual functioning. Cautioning the intellect fails to take into account more powerful and profound influences on behavior, notably the emotions. Rules that recognize the range and complexity of the decisions-making operation in an individual, even though the operation is not feasibly detectible, offer greater promise of a proper influence and significance. Rules encouraging larger ranges of information to be fed into the decision-maker also promise better 
results. The combination of these two kinds of rules affords the best protection against blackmarket thought manipulations of the trial process and spurious or misguided litigation results.

Ultimately, confidence in decisions is a matter of faith-faith in the competence of those who render decisions to observe and control all of their sense processes reasonably successfully and, if possible, with acute skill and insight. Greater latitudes in relation to trial procedures and decisions are most essentially responsible to such premises.

Psychological consistency and continuity in the litigation process is dependent upon the effective harnessing and synchronization of the various agents and instrumentalities connected with it. Litigants and their motivation require more comprehensive understanding. Attorneys require greater skills in developing "awareness" of their clients and in negotiating the process of interaction with them. The bargaining process in which attorneys engage requires a greater awareness and skill in handling other feelings beside fear, the psychological strength of power, as the means for developing influence and decision. And, trial procedure and the rules of evidence need continuing and further liberalization that they may accord with a consistent set of psychological tenets and produce more useful and desirable results.

In its present terms, litigation is indeed a psychologically discontinuous and muddled process. Fortuitously or, in a more charitable stance, fortunately, some lines of approach have been developed which make for greater consonance and skill in the use of litigation as a means of dealing with frustration and human conflict. 